East African Medical Journal Vol. 86 No. 2 February 2009

HUMAN CRYPTOSPORIDIOSIS: A REVIEW

P. O. Ayuo, MBChB, MMed, Senior Lecturer, Department of Medicine, School of Medicine, Moi University, P. O. Box 4606, Eldoret 30100, Kenya

\title{
HUMAN CRYPTOSPORIDIOSIS: A REVIEW
}

\author{
P. O. AYUO
}

\begin{abstract}
Objective: To provide an overview of risk factors, presentation and management of human cryptosporidium infection.

Data sources: Literature review was obtained through PubMed search.

Data selection: Published articles on the taxonomy of Cryptosporidium and the epidemiology, clinical presentation and management of cryptosporidiosis were reviewed.

Data extraction and synthesis: Abstracts and complete articles relevant to the objective were selected, read and analysed to extract information for this article.

Conclusions: Human cryptosporidiosis is a severe diarrhoeal disease in malnourished children and immuno-compromised adults in whom it confers poor prognosis. Management is mainly supportive as drug therapy remains elusive. Fortunately the prevalence in AIDS patients is declining due to the widespread use of combination antiretroviral therapy (cART).
\end{abstract}

\section{INTRODUCTION}

Human cryptosporidiosis is caused by infection with the Apicomplexa protozoan of the genus Cryptosporidium. Human illness was formerly thought to be caused by a single species, but molecular studies have demonstrated that several different species cause human cryptosporidiosis. Among the more common species are Cryptosporidium hominis, for which humans are the only natural host and Cryptosporidium paroum, which infects bovines as well as humans(1). However, C. canis, C. felis, C. meleagridis and C. muris have also been found in patients with HIV infection, thus having the potential to cause human disease (2). Lately, other genotypes including cervine genotype have also been implicated in human disease (3-5). Cryptosporidiosis is one of the most common causes of diarrhoea in humans with peak incidence occurring in children under two years (6). The pathogenicity of Cryptosporidium varies with the species of parasites involved and the type, age, and immune status of the host. In immuno-compromised individuals due to HIV infection, post transplant therapy or malnutrition (children), the infection is frequently chronic and can eventually lead to death $(1,7)$.

Epidemiology: Infection by Cryptosporidium has been reported around the world in both immunocompetent and immunocompromised individuals $(4,8,9)$. Transmission is usually faeco-oral, often through water contaminated by mammal faeces. In developing countries, most people are infected during childhood (6). Serologic and stool studies have documented high rates of infection in Latin America, Africa, the Middle East, and South Asia. Overall, about 13\% of stool studies submitted for parasitological studies in developing countries reveal Cryptosporidium oocysts, however, in patients with AIDS and diarrhoea the rate of cryptosporidiosis has been found to be as high as $72 \%(10,11)$. Like other opportunistic infections, the prevalence of cryptosporidiosis in AIDS patients has dropped dramatically due to wide spread use of ARVs. Humans acquire Cryptosporidium infection through several transmission routes with person to person transmission playing a major role among the elderly and paediatric populations in nursing homes and day care centres respectively (12). In rural areas infection via contact with domestic animals has been reported (13) and in urban centres in the developed countries contaminated food and / or water have been identified as sources of outbreaks (14).

Cryptosporidiosis is promoted in an environment with large numbers of infectious oocysts and susceptible hosts. Oocysts in such an environment have many possible sources ranging from domestic livestock such as cattle, sheep and horses (15) to pets such as cats and dogs (16). Wild animals also act as reservoirs as they may contaminate water or food in environments shared by their domestic counterparts (17). Infected humans some of whom may be 
asymptomatic also shed oocysts and contribute to the cycle. Most human outbreaks of water borne cryptosporidiosis are caused by the human genotype of C. parvum (18), however, C. hominis has also been reported in some instances (19) suggesting that human waste is an important source of oocyst for the outbreaks.

Cryptosporidiosis is one of the most common causes of diarrhoea in humans with peak incidence occurring in children under two years (6) and has been reported to be a major cause of morbidity and mortality throughout the world with infection outbreaks usually being linked to contaminated water (20). Young children are particularly susceptible especially in the malnourished in whom poor outcome has been confirmed in a control study in Ghana (7).

Cryptosporidiosis and HIV infection: Gastrointestinal (GI) diseases are the most common presentation of acquired immunodeficiency synd rome (AIDS) in the third world with diarrhoea and weight loss being common.

Aetiology of chronic diarrhoea in Human Immunodeficiency Virus (HIV) infected / AIDS patients as identified by many workers comprises mainly Cryptosporidium spp, Microsporidium spp and Campylobacter. While comparing children with and without HIV infection both groups having persistent diarrhoea in Uganda's Mulago Hospital, Tumwine et al (10) showed that $73.6 \%$ of HIV positive had Cryptosporidium compared to only $5.9 \%$ of those without HIV. In Venezuela, Chacin-Bonilla et al (21) in a case control study involving 103 HIV infected outpatients found Cryptosporidium in 13.6\%. In Nairobi, Kenya (22) among 75 consecutive in-patients with HIV and diarrhoea, 52\% had pathogens with Cryptosporidium spp being the most commont accounting for $17 \%$. In a prospective study involving HIV infected and uninfected children with diarrhoea in Thailand (23) the most common parasites were Cryptosporidium and Microsporidium. Thus cryptosporidiosis is one of the major causes of chronic diarrhoea especially in HIV infected individuals.

Published studies describing the prevalence and epidemiology of cryptosporidiosis in patients with HIV infection present markedly different estimates ranging from 0 to $100 \%$ as reviewed by Hunter and Nichols (24). However, these studies are unanimous in finding that the risk of infection increases with decreasing immunity as measured by CD4+ $\mathrm{T}$ lymphocyte cell count (25). In addition, various social and behavioural factors such as sexual behaviour, gender and rearing pets and livestock have also been reported to increase risk of infection. In a multi- centre European study the risk of cryptosporidiosis was significantly lower for intra-venous drug users than homosexual men (RR 0.34; 95\% CI 0.22 - 0.54) and for women than men (RR 0.43; 95\%CI 0.21 - 0.87) (26).
A large US study (27) has shown that prevalence of cryptosporidiosis washigherin persons whoacquired HIV through sexual contact $(3.9 \% \mathrm{p}<0.01)$ than those with other HIV exposure categories $(2.6 \% \mathrm{p}<0.01)$. Keeping pets also poses a risk as reported by Glaser, et al (28).

Blanshard et al (29) described various presentations of cryptosporidiosis in HIV positive patients in London; 5\% of all patients and $21 \%$ of all AIDS patients had cryptosporidiosis. Transient infection was noted in $28.7 \%$ chronic disease in $59.7 \%$, asymptomatic disease in $3.9 \%$ and fulminant disease in $7.8 \%$. In later studies, US workers found chronic diarrhoea in $36 \%$, cholera like (fulminant) disease in 33\% and transient diarrhoea in 15\% with shorter survival among the infected (30). Only those with CD4+ T-lymphocytes of less than 50 cells $/ \mathrm{ml}$ get fulminant disease (31). Outcome of Cryptosporidiosis in HIV infected patients is related to CD4+ T-lymphocyte count and haematocrit level at the time of diagnosis. Colford, et al (32) have shown that the median survival of those with CD4 count of $>53 / \mathrm{ml}$ and haematocrit of $>37 \%$ was 1,119 days compared to 204 days for those with less. In Kenya, Mwachari et al (22) have demonstrated that among HIV positive patients with diarrhoea, the presence of Cryptosporidium was the single most significant predictor of death when compared with other enteric infections.

Pathophysiology: Cryptosporidium oocysts are highly infectious, requiring only $10^{1}-10^{3}$ oocysts to cause human disease (11). Upon oocyte excystation, four sporozoites are released which adhere to the surface of intestinal mucosa (33) with the aid of sporozoitespecific lectin adherence factor before gaining residence in the intracellular space but outside the cytoplasm (11). It is suspected that the parasite stimulates the mucosal cells to release cytokines that activate resident phagocytes (33). Host response to the infection includes a combination of increased intestinal permeability, chloride secretion and malabsorption resulting in diarrhoea $(6,33)$. In patients with AIDS or any form of immune deficiency, the biliary tract may be involved.

Clinical presentation: After an incubation period of 5-10 days (range 2-28 days), the patient develops watery diarrhoea, which may be associated with abdominal cramps and a low-grade fever lasting for about 5-10 days but may persist for 2-4 weeks. Patients with AIDS and very low CD4 cell counts may develop profuse, cholera-like diarrhoea, which can be complicated by volume depletion and malabsorption. Biliary tract involvement which may include acalculous cholecystitis, sclerosing cholangitis, papillary stenosis, or pancreatitis seen in AIDS patients with very low CD4 cell counts and children with X-linked 
immunodeficiency with hyper-IgMis associated with right upper quadrant pain, nausea, and vomiting. Some patients remain asymptomatic.

Physical findings are non-specific with low grade fever and temperature higher than $39^{\circ} \mathrm{C}$ is not characteristic of cryptosporidiosis. Signs of volume depletion or wasting from malabsorption may be found.

Investigations: Most tests to detect Cryptosporidium involve direct microscopic detection of the parasite in tissues or faecal specimen. Modified acid-fast staining of stool (red-stained round oocysts against a bluegreen background) is the commonly used laboratory test due to its low cost and simple methodology (34). However, the staining methods have shown low sensitivity ranging from $33.3 \%$ to $41 \%$ with stool specimen (35). The relatively low sensitivity with faeces can be improved tremendously by examination of prepared slides under UV light with a rhodamine (540-560 nm) filter (36). Antibody based tests are also availablebut more expensive than staining techniques with similar sensitivity and specificity (37).

Antigen-detection assays are more sensitive $(35,38)$ and include immunofluorescent assays, enzyme-linked immunosorbent assay (ELISA), immunochromatographic tests as well as Polymerase Chain Reaction (PCR) (39) but are not readily available for clinical use. Stool culture is necessary to rule out the presence of other bacterial pathogens. Other tests like createnine, urea, serum proteins, full blood count, $\mathrm{CD} 4$ e.t.c. may be used to gauge severity of the condition and immune status. Imaging and endoscopic studies like ERCP are needed when extraintestinal complications are suspected.

Histology of the small intestine shows the parasite projecting from the brush border of the mucosal surface but this examination is not required to confirm the diagnosis of cryptosporidiosis. The parasites may also be identified in bile or biliary tract biopsies.

Treatment: There is lack of effective chemotherapeutic agents or vaccines against Cryptosporidium (3). Intracellular location and innate resistance to many agents have rendered the treatment of Cryptosporidiosis difficult and frustrating (3). Most agents that have been investigated as treatments for cryptosporidiosis received mixed success (40). Paromomycin an amino glycoside antibiotic with antibacterial spectrum similar to that of neomycin has been used as an oral, first-line agent in cryptosporidiosis with mixed results.

White et al. (41) reported a significant reduction in stool frequency and oocyst excretion during treatment. In contrast, Hewitt et al. (42) compared paromomycin with placebo in 35 cryptosporidiosis cases with CD4 cells of less than 150 cells $/ \mathrm{mm}^{3}$ and found no difference between the two arms in terms of diarrhoea, weight or oocyst excretion. Interestingly, paromomycin, alone or in combination with Azithromycin has been accepted for symptom control. Nevertheless, the combination is too expensive.

Oral spiramycin, a macrolide antibiotic, showed promise initially but efficacy in HIV-positive patients has never been demonstrated (43). Azithromycin, another macrolide, has shown mixed results as reported by various workers. Kadappu et al (44) reported good clinical response after a seven day course in 13 HIV -positive individuals, but oocyst shedding persisted in majority even after two weeks. Allam et al (45) and Trad et al. (46) have reported success with azithromycin with up to $99 \%$ reduction in oocysts after three weeks of treatment, whereas, others have failed to record any significant response to the drug $(47,48)$. Clarithromycin of the same group, has shown some promise as a prophylactic agent (49) however, in one retrospective analysis involving 2,288 patients clarithromycin did not decrease risk of cryptosporidiosis (50). Sprinz et al. (51) found that $50 \%$ of 24 patients had complete symptom remission and $29 \%$ partial response when given four weeks of roxithromycin therapy.

So far the most promising agent in recent years is nitazoxanide (2-acetyloxy-N-(5-nitro-2 thiazolyl) benzamide) a synthetic antiparasitic agent for oral administration that is rapidly hydrolysed to its active metabolite tizoxanide. Amadi et al. (52) in random placebo controlled study involving 50 HIV -positive and $50 \mathrm{HIV}$-negative children with cryptosporidiosis confirmed significant efficacy and reduced mortality in nitazoxanide arm. Using higher doses though, Rossignol et al. (53) confirmed nitazoxanide to be significantly better than placebo. More recently nitazoxanide, improved clinical outcomes in $56 \%$ of HIV negative malnourished Zambian children with quick parasite clearance rate (54). Other agents with activity against Cryptosporidium include Ionophores (lasalocid and maduramycin). Passive antibody immunotherapy with bovine colostrum from cows hyperimmunised with Cryptosporidial cysts has been tried with limited success (55).

Symptomatic therapy includes replacement of fluids, nutrition and treatment of diarrhoea. Antidiarrhoeal agents; Loperamide, diphenoxylateatropine, somatostatin analogues (octreotide) or opiates are used in combination with antiparasitic agents. Attention to nutritional aspects of patient care is crucial because malnutrition can cause death. Lactose intolerance is common in cryptosporidiosis, and lactose-containing foods should be avoided. Patients with acalculous cholecystitis should generally be treated with cholecystectomy. 
Prevention: Drinking water, especially for AIDS patients should be purified by using 1-micron water filters in countries with high risk of transmission (56). Avoidance of newborn animals including domestic ones helps in preventing transmission specifically new pets for patients with AIDS should be older than six months and should not have diarrhoea. Hand washing should also be practiced by those in health care and child care to avoid faeco-oral transmission

Prognosis: Children with persistent diarrhoea develop worsening malnutrition, which may result in cognitive and fitness problems that persist for years (33). Chronic cryptosporidiosis may be complicated by biliary tract disease, malabsorption, and death in AIDS patients and malnourished children. Prolonged diarrhoea (> $1 \mathrm{mo}$ ) and biliary disease indicate a poor prognosis in patients with AIDS. In immunocompetent individuals Cryptosporidium causes self limiting watery or mucoid diarrhoea with abdominal pain (24).

\section{CONCLUSION}

Human cryptosporidiosisis a severe diarrhoealdisease in malnourished children and immunocompromised adults in whom it confers poor prognosis. Management is mainly supportive as drug therapy remains elusive. Fortunately the prevalence in AIDS patients is declining due to the widespread use of combination antiretroviral therapy (cART).

\section{REFERENCES}

1. Xiao, L., Fayer, R., Ryan, U. and Upton, S. J. Cryptosporidium taxonomy: Recent advances and implications for Public Health. Clin. Micro. Rev. 2004; 17: 72 - 97.

2. Matos, O., Alves, M., Xiao, L., Cama, V. and Antunes, F. Cryptosporidium felis and C. meleagridis in persons with HIV, Portugal. Emerg. Infect. Dis. 2004; 10: 2256-2257.

3. Smith, H. V. and Corcoran, G. D. New drugs and treatment for cryptosporidiosis. Curr. Opin. Infect. Dis. 2004: 17: 557 - 564.

4. Caccio, S.M. Molecular epidemiology of human cryptosporidiosis. Parassitologia. 2005; 47: 185-192.

5. Trotz-Williams, L. A., Martin, D. S., Gatei, W., et al. Genotype and subtype analyses of Cryptosporidium isolates from dairy calves and humans in Ontario. Parasitol. Res. 2006; 99: 346-352.

6. Bern, C., Hernandez, B., Lopez, M.B., et al. The contrasting epidemiology of Cyclospora and Cryptosporidium among outpatients in Guatemala. Am. J. Trop. Med. Hyg. 2000; 63: 231 - 235.

7. Adjei, A. A., Armah, H., Rodrigues, O., et al. Cryptosporidium Spp., a frequent cause of diarrhoea among children at the Korle-Bu Teaching Hospital, Accra, Ghana. Japan. J. Infect. Dis. 2004; 57: 216-219.

8. Kosek, M., Alcantara, C., Lima, A. A. and Guerrant, R. L. Cryptosporidiosis: an update. Lancet. Infect. Dis. 2001; 1: 261-269.
9. Gatei, W., Wamae, C. N., Mbae, C., et al. Cryptosporidiosis: Prevalence, genotype analysis, and symptoms associated with infections in children in Kenya. Am. J. Trop. Med. Hyg. 2006; 75: 78-82.

10. Tumwine, J. K., Kekitiinwa, A., Bakeera-Kitaka, S., et al. Cryptosporidiosis and microsporidiosis in Ugandan children with persistent diarrhoea with and without concurrent infection with HIV. Am. J. Trop. Med. Hyg. 2005; 73: 921- 925.

11. Nell, M.A., Rice, S. K., Ahmad, N.V. and Flanigan, T. P. Cryptosporidiosis: an unrecognized cause of diarrhoea in elderly hospitalized patients. Clin. Infect. Dis. 1996; 27: 108 - 170.

12. Tangerman, R. H., Gordon, S., Wiesman, P. and Kreckma, L. An outbreak of Cryptosporidiosis in a day care centre in Georgia. Am. J. Epidem. 1991; 133: 471 - 476.

13. Miron, D., Kenes, J. and Dagan, R. Calves as a source of an outbreak of Cryptosporidiosis among young children in an agricultural closed community. Paediatr Infect. Dis. J. 1991; 10: 438 -441.

14. Gallaher, M. M., Herndon, J. L., Nims, L. J., et al. Cryptosporidiosis and surface water. Am. J. Public Health 1989; 79: 39 - 42.

15. Xiao, L. and Herd, R. P. Epidemiology of equine Cryptosporidium and Giardia infections. Equine Vet. J. 1994; 26: 14 -17.

16. Sargent, K. D., Morgan, U. M., Elliot, A. and Andrew Thomson, R. C. Morphological and genetic characterization of Cryptosporidium oocysts from domestic cats. Vet. Parasitol. 1998; 77: 221 - 227.

17. Rickard, L. G., Siefker, C., Boyle, C. R. and Gentz, E. J. The prevalence of Cryptosporidium and Giardia spp in faecal samples from free ranging white tailed deer (Odocoileus virginianus) in the Southern United States. J. Vet. Diagn. Invest. 1999; 11: $65-72$.

18. Suleiman, I. M., Xiao, L., Yang, C., et al. Differentiation of human from animal isolates of Cryptosporidium paroum. Emerg. Infect. Dis. 1998; 4: 681 - 685.

19. McLauchlin, J., Amar, C., Pedraza-Diaz, S. and Nichols, G.L. Molecular epidemiological analysis of Cryptosporidium spp. in the United Kingdom: results of genotyping Cryptosporidium spp. in 1,705 fecal samples from humans and 105 fecal samples from livestock animals. J. Clin. Micro. 2000; 38: 3984-3990.

20. Laubach, H.E., Bentley, C. Z., Ginter, E. L., Spalter, J. S. and Jensen, L. A. A study of risk factors associated with the prevalence of Cryptosporidium in villages around Lake Atitlan, Guatemala. Braz. J. Infect. Dis. 2004; 8: 319-323.

21. Chacin-Bonilla, L., Panunzio, A.P., Monsalve-Castillo, F.M., et al. Microsporidiosis in Venezuela: prevalence of intestinal microsporidiosis and its contribution to diarrhea in a group of human immunodeficiency virus-infected patients from Zulia State. Am. J. Trop. Med. Hyg. 2006; 74: 482-486.

22. Mwachari, C., Batchelor, B. I., Paul, J., et al. Chronic diarrhoea among HIV infected adult patients in Nairobi, Kenya. J. Infect. 1998; 37: 48-53.

23. Chokephaibulkit, K., Wanachiwanawin, D., Tosasuk, K., et al. Intestinal parasitic infections among human immunodeficiency virus- infected and -uninfected children hospitalized with 
diarrhoea in Bangkok, Thailand. Southeast. Asian. J. Trop. Med. Pub. Health. 2001; 32: 770 -775.

24. Hunter, P. R. and Nichols, G. Epidemiology and clinical features of cryptosporidium infection in immunocompromised patients. Clin. Microbiol. Rev. 2002; 15: 145 -154.

25. Navin, T.R., Weber, R., Vugia, D.J., etal.Declining CD4+ $\mathrm{T}$-lymphocyte counts are associated withincreased risk of enteric parasitosis and chronic diarrhoea: results of a 3 year longitudinal study. J. Acquired Immune Defic. Syndr. 1999; 20: 154 - 159.

26. Pedersen, C., Danner, S., Lazzarani, A., et al. Epidemiology of Cryptosporidiosis among European AIDS patients. Genitourin. Med. 1996; 72: 128 - 131.

27. Sorvilo, F.J., Lieb, L. E., Kerndt, P. R. and Ash, L. R. Epidemiology of cryptosporidiosis among patients with AIDS in Los Angeles County. Am. J. Trop. Med. Hyg. 1994; 51: 326 - 331.

28. Glaser, C. A., Safrin, S., Reingold, A. and Newman, T.B.Association between Cryptosporidium infection and animal exposure in HIV infected individuals. J. Acquired Immun. Defic. Syndr. 1998; 17: 79 - 82.

29. Blanshard, C., Jackson, A. M., Shenson, D. C., Francis, N. and Gazzard, B. G. Cryptosporidiosis in HIV sero positive patients. Q. J. Med. 1992; 85: $813-823$.

30. Manabe, Y. C., Clark, D. P., Moore, R. D., et al. Cryptosporidiosis in patients with AIDS. Correlates of disease and survival. Clin. Infec. Dis. 1998; 27: $536-542$.

31. McGowan, I., Hawkins, A. S. and Weller, I. V. The natural history of Cryptosporidial diarrhoea in HIV infected patients. AIDS. 1993; 7: 349 -354.

32. Colford, J. M., Jr., Tager, I. B., Hirozawa, A. M., et al. Cryptosporidiosis among patients infected with human immunodeficiency virus. Factors related to symptomatic infection and survival. Am. J. Epidemiol 1996; 144: 807 - 816.

33. Goodgame, R. W. Understanding intestinal sporeforming protozoa: Cryptosporidia, Microsporidia, Isospora and Cyclospora. Annals. Intern. Med. 1996; 124: 429 - 441.

34. Ramirez, N. E., Ward, L.A. and Sreevatsan, S.Areview of the biology and epidemiology of cryptosporidiosis in humans and animals. Microbes and Infection. 2004; 6: 773-785.

35. Kaushik, K., Khurana, S., Wanchu, A. and Malla, N. Evaluation of staining techniques, antigen detection and nested PCR for the diagnosis of cryptosporidiosis in HIV seropositive and seronegative patients. Acta. Trop. 2008; 107: 1-7.

36. Nielsen, C. K. and Ward, L. A. Enhanced detection of Cryptosporidium parvum in the acid- fast stain. J. Vet. Diagn. Invest. 1999; 11: 567-569.

37. Garcia, L. S. and Shimizu, R. Y. Evaluation of nine immunoassay kits (enzyme immunoassay and direct fluorescence) for detection of Giardia lamblia and Cryptosporidium parvum in human fecal specimens. J. Clin. Microbiol. 1997; 35: 1526- 1529.

38. el-Shazly, A. M., Gabr, A., Mahmoud, M. S., Aziz, S. S. and Saleh, W. A. The use of Ziehl-Neelsen stain, enzyme-linked immunosorbent assay and nested polymerase chain reaction in diagnosis of cryptosporidiosis in immuno-competent, compromised patients. J. Egypt. Soc. Parasitol. 2002; 32: $155-166$.
39. da Silva, A. J., Bornay-Llinares, F. J., Moura, I. N., et al. Fast and reliable extraction of protozoan parasite DNA from fecal specimens. Mol. Diagn. 1999; 4: 57-64.

40. Mead, J. Cryptosporidiosis and the challenges of chemotherapy. Drug Resist Update. 2002; 5: 47-57.

41. White, A. C. Jr, Chappell, C. L., Hayat, C. S., et al. Paromomycin for cryptosporidiosis in AIDS: a prospective, double-blind trial. J. Infect. Dis. 1994; 170: 419-424.

42. Hewitt, R. G., Yiannoutsos, C. T.,Higgs, E.S., et al. AIDS Clinical Trial Group. Paromomycin: no more effective than placebo for treatment of cryptosporidiosis in patients with advanced human immunodeficiency virus infection. Clin. Infect. Dis. 2000; 31: 1084-1092.

43. Blagbum, B. and Soave, R. Prophylaxis and chemotherapy: human and animal. In: Fayer R, editor. Cryptosporidium and cryptosporidiosis. Boca Raton, FL: CRC Press; 1997. pp. 111-128.

44. Kadappu, K. K., Nagaraja, M.V., Rao, P. V. and Shastry, B.A.Azithromycin as treatment for cryptosporidiosis in human immunodeficiency virus disease. J. Postgrad Med. 2002; 48: 179-181.

45. Allam, A. F. and Shehab, A. Y. Efficacy of azithromycin, praziquantel and mirazid in treatment of cryptosporidiosis in school children. J. Egypt. Soc. Parasitol. 2002; 32: 969- 978.

46. Trad, O., Jumaa, P., Uduman, S. and Nawaz, A. Eradication of Cryptosporidium in four children with acute lymphoblastic leukaemia. J. Trop. Paed. 2003; 49: 128-130.

47. Blanshard, C., Shanson, D. and Gazzard, B. Pilot studies of azithromycin, letazuril and paromomycin in the treatment of cryptosporidiosis. Int. J. STD. AIDS 1997; 8: 124-129.

48. Dunne, M., Williams, D. and Young, L. Azithromycin and the treatment of opportunistic infections. Rev. Contemp. Pharmacother. 1994; 5: 373-378.

49. Jordan, E. Clarithromycin prophylaxis against Cryptosporidium enteritis in patients with AIDS. J. Natl. Med. Assoc. 1996; 100: 370-372.

50. Fichtenbaum, C. J., Zackin, R., Feinberg, J., Benson, C. and Griffiths, J. K. AIDS Clinical Trials Group New Works Concept Sheet Team 064. Rifabutin but not clarithromycin prevents cryptosporidiosis in persons with advanced HIV infection. AIDS. 2000; 14: 2889-2893.

51. Sprinz, E., Mallman, R., Barcellos, S., et al. AIDS related cryptosporidial diarrhoea: an open study with roxithromycin. J. Antimicrob. Chemother. 1998; 41 (Suppl B): 85-91.

52. Amadi, B., Mwiya, M., Musuku, J., et al. Effect of nitazoxanide on morbidity and mortality in Zambian children with cryptosporidiosis: a randomised controlled trial. Lancet. 2002; 360: 1375-1380.

53. Rossignol, J.F., Hidalgo, H., Feregrino, M., et al. A double-'blind' placebo-controlled study of nitazoxanide in the treatment of cryptosporidial diarrhoea in AIDS patients in Mexico. Trans. R. Soc. Trop. Med. Hyg. 1998; 92: 663-666.

54. Fox, L. M. and Saravolatz, L.D. Nitazoxanide: a new thiazolide antiparasitic agent. Clin. Infect. Dis. 2005; 40: 1173 - 1180.

55. Wiwanitkit, V. Intestinal parasite infestation in HIV infected patients. Curr. HIV Res. 2006; 4: 87 - 96.

56. Dillingham, R. A., Lima, A. A. and Guerrant, R. L. Cryptosporidiosis: epidemic and impact. Microbes and Infect. 2002; 4: 1059-1066. 